\section{New Split-Winding Doubly Salient Permanent Magnet Motor Drive}

MING CHENG, Senior Member, IEEE

K. T. CHAU, Member IEEE

C. C. CHAN, Fellow, IEEE

The University of Hong Kong

A new split-winding doubly salient permanent magnet (DSPM) motor drive is proposed. This DSPM motor drive offers the advantages of high power density, high efficiency, and wide speed range. The corresponding operation, analysis, implementation, and experimentation are successively presented. Finally, experimental results are used to confirm that the proposed DSPM motor drive offers high efficiency over a wide output power range, exhibits good dynamic performance, and extends the constant-power operation range significantly.

Manuscript received November 7, 2001; revised September 24, 2002; released for publication October 10, 2002.

IEEE Log No. T-AES/39/1/808665.

Refereeing of this contribution was handled by I. Batarseh.

This work was supported in part by a grant from the RGC Project HKU 7035/01E, Hong Kong, China, and a grant from the NSFC Project 59507001, China.

Authors' current addresses: M. Cheng, Dept. of Electrical Engineering, Southeast University, Nanjing 210096, China; K. T. Chau, Dept. of Electrical and Electronic Engineering, The University of Hong Kong, Pokfulam Road, Hong Kong, E-mail: (ktchau@eee.hku.hk).

0018-9251/03/\$17.00 (c) 2003 IEEE

\section{INTRODUCTION}

It has been a long-lived objective to develop an advanced motor drive that combines the advantages of the dc motor drive of good speed controllability as well as the ac motor drive of high reliability, robustness, and maintenance free for aerospace and electric vehicle (EV) applications $[1,2]$. With the rapid development of power electronics and microelectronics technologies, the advancement of control, and the advent of new materials, many advanced motor drives with improved efficiency using permanent magnets in the motor have been developed [2, 3]. One of those high efficiency advanced motors is the newly proposed doubly salient permanent magnet (DSPM) motor [4]. The recent literature has shown that the DSPM motor is of high efficiency, high power density, and simple structure [4-9].

In [7], an 8/6-pole DSPM motor was proposed. Its advantages over a 6/4-pole one, namely higher power density, wider speed range, less torque ripple and lower current magnitude, were also revealed. However, similar to most permanent magnetic (PM) brushless motors, this DSPM motor suffered from a limited constant power operation range due to the fact that the field control capability of PM excitation was much more difficult to achieve than that of wound field excitation. Thus, a topology to extend the constant-power operation range of the DSPM motor, namely the split-winding configuration, was proposed in [8]. The features of this split-winding topology as compared with the flux weakening techniques were also discussed. Then, the design and analysis of this DSPM motor were presented in [9]. The corresponding output power equation was analytically derived. The initial sizing of motor dimensions and parameters, namely the core diameter, stack length, PM size, and winding turns, were particularly discussed. Moreover, finite element analysis of this motor, taking into account the leakage flux outside the stator circumference, was presented.

The purpose of this work is to propose and implement a new 4-phase 8/6-pole split-winding DSPM motor drive, which not only offers the advantages of high efficiency, high power density, and high reliability but also the capability to achieve constant-power operation at high speeds. In Section II, the operating principle of the proposed 4-phase 8/6-pole DSPM motor is described. Then, the corresponding theoretical analysis is given in Section III. Section IV is devoted to presenting the proposed control strategy. The method of detection for the rotor position and motor speed is specifically discussed in Section V, while the whole system implementation is discussed in Section VI. To verify the system performance, simulation and experimental results 


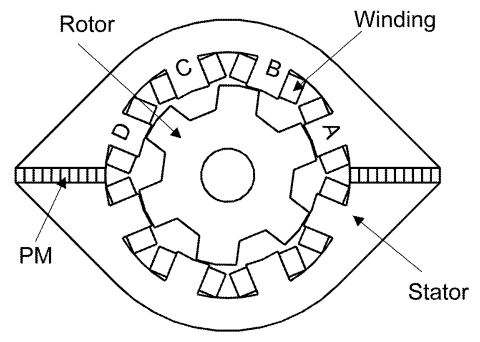

(a)

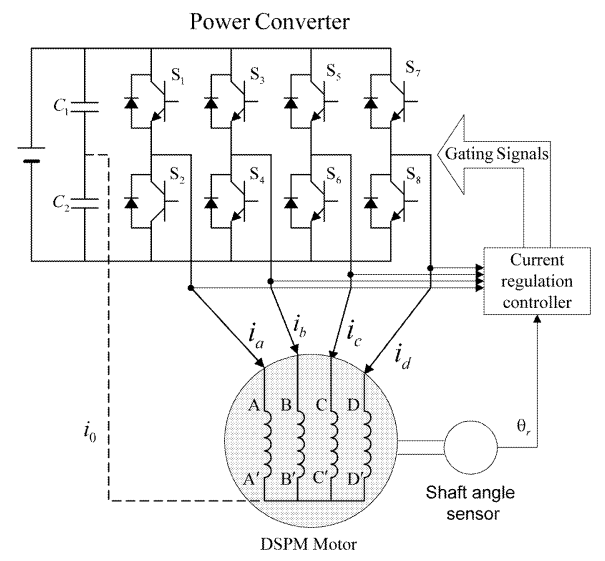

(b)

Fig. 1. Proposed DSPM motor drive. (a) Motor configuration. (b) System arrangement.

are presented in Section VII. Finally, a conclusion is drawn in Section VIII.

\section{OPERATING PRINCIPLE}

Fig. 1(a) shows the cross section of the newly proposed DSPM motor and Fig. 1(b) illustrates the arrangement of the motor drive system. It is a 4-phase 8/6-pole DSPM motor, and essentially adopts the same structure as a switched reluctance (SR) motor but with PMs placed in the stator. There are neither PMs nor windings in the rotor. Obviously, the machine is of simple structure and free of maintenance, and is capable of working at high speeds. In addition, since the stator windings are of the concentrated type, the overhanging part of the coil is short, resulting in the saving of copper as well as the reduction of copper loss. Particularly, the placement of both PMs and windings in the stator is favorable to machine cooling that is desirable for the aerospace and EV applications where the ambient temperature of the machine may be high.

Under the assumptions that the fringing offset is negligible and the permeability of the core is infinite, a linear variation of PM flux linkage is established in the stator windings at no-load. The corresponding theoretical waveforms of PM flux and phase current are shown in Fig. 2. When the PM flux linkage increases with the rotor position angle, a positive current is applied to the phase winding, resulting in a

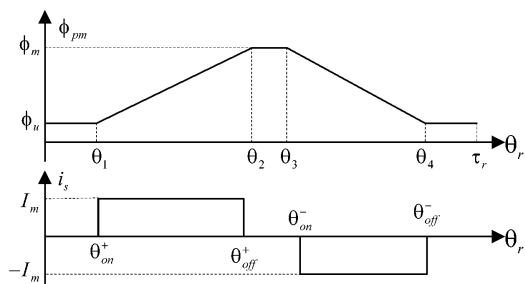

Fig. 2. Theoretical flux and current waveforms.

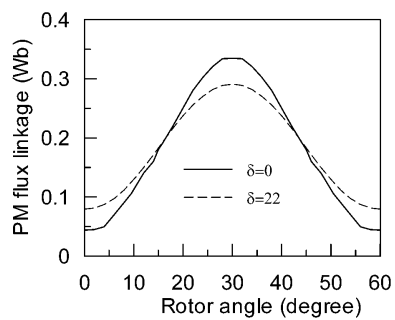

(a)

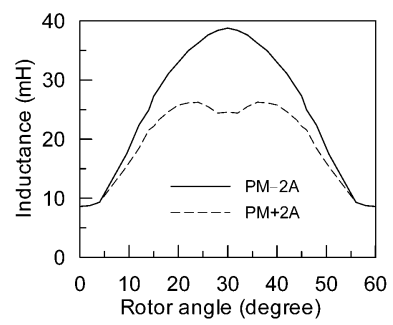

(b)

Fig. 3. Static characteristics by FEM. (a) PM flux linkage. (b) Inductance.

positive torque. When the PM flux linkage decreases, a negative current is applied to the phase winding, also resulting in a positive torque. This feature in torque production distinguishes the DSPM motor from the SR motor.

\section{THEORETICAL ANALYSIS}

\section{A. Electromagnetic-Field Analysis}

The magnetic field of the proposed DSPM motor can readily be analyzed using the finite element method (FEM). Hence, the PM flux linkage and the phase inductance can be deduced. Without elaborating the well-known FEM, Fig. 3 shows the PM flux linkage and the phase inductance as a function of the rotor position using the FEM. In Fig. 3(a), $\delta$ is the rotor skewing angle in mechanical degree, whereas in Fig. 3(b), "PM $+2 \mathrm{~A}$ " and "PM $-2 \mathrm{~A}$ " denote the strengthening and weakening actions of the armature flux at a current of $2 \mathrm{~A}$ to the PM flux, respectively. Obviously, the phase inductance depends on not only the rotor position, but also the strengthening/weakening action of the armature flux to the PM flux. Moreover, the no-load back EMF can be easily derived by differentiating the PM flux linkage [9]. 


\section{B. Mathematical Equations}

The applied voltages at the terminal of the DSPM motor can be described as

$$
\bar{U}=\bar{R} \bar{I}+\frac{d \bar{\Psi}}{d t}
$$

where $\bar{U}=\left[u_{1}, u_{2}, u_{3}, u_{4}\right]^{T}$ is the voltage matrix, $\bar{R}=$ $\operatorname{diag}\left[r_{1}, r_{2}, r_{3}, r_{4}\right]$ the resistance matrix, $\bar{I}=\left[i_{1}, i_{2}, i_{3}, i_{4}\right]^{T}$ the current matrix, $\bar{\Psi}=\bar{L} \bar{I}+\bar{\Psi}_{m}$ the flux linkage matrix, and $\bar{\Psi}_{m}$ the PM flux linkage vector. Also, $\bar{L}$ and $\bar{\Psi}_{m}$ can be written as $\bar{L}=\left[L_{i j}\right],(i=1 \sim 4, j=$ $1 \sim 4)$ and $\bar{\Psi}_{m}=\left[\psi_{m 1}, \psi_{m 2}, \psi_{m 3}, \psi_{m 4}\right]^{T}$. When both of them are considered to be spatially dependent only and independent of the stator current, it yields

$$
\frac{d \bar{\Psi}}{d t}=\bar{L} \frac{d \bar{I}}{d t}+\frac{d \bar{L}}{d t} \bar{I}+\frac{d \bar{\Psi}_{m}}{d t}=\bar{L} \frac{d \bar{I}}{d t}+\frac{d \bar{L}}{d \theta_{r}} \bar{I} \omega_{r}+\frac{d \bar{\Psi}_{m}}{d \theta_{r}} \omega_{r}
$$

where $\omega_{r}$ is the mechanical angular velocity of the motor, and $\theta_{r}$ is the mechanical rotor position angle defined as the angle between the central lines of stator pole and rotor slot. Thus, by using (2), the dynamic equation given by (1) can be rewritten as

$$
\frac{d \bar{I}}{d t}=-\bar{L}^{-1}\left(\bar{R}+\frac{d \bar{L}}{d \theta_{r}} \omega_{r}\right) \bar{I}+\bar{L}^{-1}\left(\bar{U}-\frac{d \bar{\Psi}_{m}}{d \theta_{r}} \omega_{r}\right) .
$$

By employing the coenergy method, the torque equation of the motor is obtained as

$$
\begin{aligned}
T_{e} & =\frac{\partial W^{\prime}}{\partial \theta_{r}}=\frac{\partial}{\partial \theta_{r}}\left(\frac{1}{2} \bar{I}^{T} \bar{L} \bar{I}+\bar{\Psi}_{m}^{T} \bar{I}\right) \\
& =\frac{1}{2} \bar{I}^{T}\left(\frac{\partial}{\partial \theta_{r}} \bar{L}\right) \bar{I}+\left(\frac{\partial}{\partial \theta_{r}} \bar{\Psi}_{m}\right)^{T} \bar{I}=T_{r}+T_{p m}
\end{aligned}
$$

where $T_{e}$ is the total electromagnetic torque, $T_{r}=$ $\frac{1}{2} \bar{I}^{T}\left(\left(\partial / \partial \theta_{r}\right) \bar{L}\right) \bar{I}$ represents the reluctance torque component due to the variation of inductances, and $T_{p m}=\left(\left(\partial / \partial \theta_{r}\right) \bar{\Psi}_{m}\right)^{T} \bar{I}$ is the PM torque component due to the interaction between the winding current and the PM flux.

Having derived the electromagnetic torque, the motion equation of the DSPM motor can be expressed as

$$
\frac{d \omega_{r}}{d t}=\frac{1}{J}\left(T_{e}-T_{l}-B_{v} \omega_{r}\right)
$$

where $T_{l}$ is the load torque, $B_{v}$ the viscous-damping coefficient, and $J$ the moment of the inertia. By making use of (1)-(5), the behavior of the DSPM motor can be determined.

By neglecting the mutual inductances of the motor, (3) can be decoupled among phases and is given by

$$
\frac{d i}{d t}=-\frac{1}{L}\left(r+\frac{d L}{d \theta_{r}} \omega_{r}\right) i+\frac{1}{L}\left(U-\frac{d \psi_{m}}{d \theta_{r}} \omega_{r}\right)
$$

where $r, L$, and $U$ are the resistance, self-inductance, and applied voltage of each phase winding, respectively. Taking $L$ as its average value in one stroke, the analytical solution of (6) can thus be obtained as

$$
\begin{aligned}
i= & \left(U-\frac{d \psi_{m}}{d \theta_{r}} \omega_{r}\right)\left\{1-\exp \left[-\frac{1}{L}\left(r+\frac{d L}{d \theta_{r}} \omega_{r}\right) t\right]\right\} / \\
& \left(r+\frac{d L}{d \theta_{r}} \omega_{r}\right) .
\end{aligned}
$$

Hence, the steady-state phase current is given by

$$
I=\left(U-\frac{d \psi_{m}}{d \theta_{r}} \omega_{r}\right) /\left(r+\frac{d L}{d \theta_{r}} \omega_{r}\right) .
$$

According to the operating principle of the DSPM motor, a positive current should be applied to the phase winding when the corresponding flux linkage is increasing, and vice versa. To keep a positive current at the first stroke and a negative current at the second stroke, the following condition is necessary:

$$
|U|-\left|\frac{d \psi_{m}}{d \theta_{r}}\right| \omega_{r} \geq 0
$$

It illustrates that for a given supply voltage, there is a speed limit $\omega_{r \max }$ as represented by

$$
\omega_{r \max }=|U| /\left|\frac{d \psi_{m}}{d \theta_{r}}\right| .
$$

The corresponding $d \psi_{m} / d \theta_{r}$ can be approximately expressed as

$$
\frac{d \psi_{m}}{d \theta_{r}}=k N_{\mathrm{ph}} B_{g}
$$

where $k$ is a constant governed by the machine dimensions, $N_{\text {ph }}$ is the number of winding turns per phase, and $B_{g}$ is flux density in the airgap. Thus, (10) can be deduced as

$$
\omega_{r \max }=\frac{|U|}{k N_{\mathrm{ph}} B_{g}}
$$

which indicates that the speed limit can be extended by reducing the number of winding turns per phase. This principle is suitable to all PM brushless motors in theory, but not practical for those conventional ones, such as PM synchronous motors, because they adopt the distributed windings and the corresponding change of winding turns is very difficult. However, the DSPM motor inherently adopts the concentrated winding which can allow changing the number of winding turns by employing split windings. Fig. 4 shows the schematic connection of the proposed split windings. When the switch $K_{1}$ is on, the whole windings are functional, whereas the switch $K_{2}$ can be turned on so that the winding turns per phase are reduced to $50 \%$. These switches may be manually or electronically operated according to the requirements 


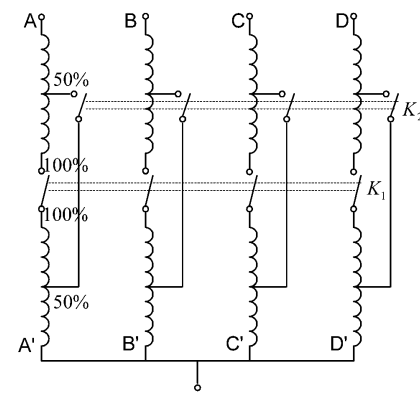

Fig. 4. Schematic connection of split windings.

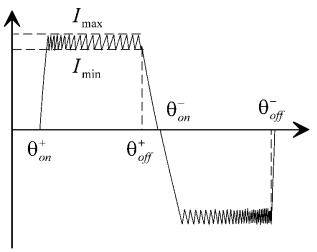

(a)

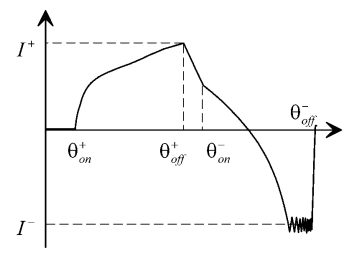

(b)

Fig. 5. Typical current waveforms. (a) CCC mode. (b) APC mode.

of application and cost. In the following experiment, manual operation is adopted for the sake of simplicity.

\section{CONTROL STRATEGY}

The control strategy of the DSPM motor drive consists of two schemes, namely chopping current control (CCC) and angle position control (APC), respectively for constant-torque operation at speeds below the base speed and constant-power operation at speeds equal to or above the base speed. As illustrated in Fig. 2, the operating angles, namely $\theta_{\text {on }}^{+}, \theta_{\text {off }}^{+}, \theta_{\text {on }}^{-}$, and $\theta_{\text {off }}^{-}$, are those control variables to shape the phase current.

Fig. 5 shows the typical current waveforms at the CCC and APC modes, respectively. During the low-speed CCC mode, the phase current is kept constant in each stroke by current chopping. The control angles are fixed, while the torque control is achieved by changing the current reference. During the high-speed APC mode, the phase current can no longer be maintained constant because of the excessive PM-induced electromotive force (EMF). In the positive stroke, the phase current initially rises very fast and then slows down with the increase in inductance. Notice that the current may not be able to reach its steady-state value before the winding is

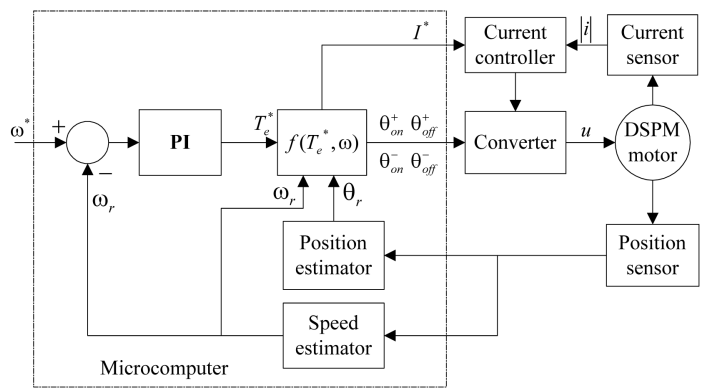

Fig. 6. Control block diagram.

switched off at the rotor position angle $\theta_{\text {off }}^{+}$. Then, the current falls slowly to zero due to the occurrence of high inductance. In the negative stroke, however, the current rises rapidly to its steady-state value. Once the winding is switched off at $\theta_{\text {off }}^{-}$, the current goes to zero very fast due to the occurrence of low inductance. Thus, in the APC mode, the current reference is kept constant at a high level, and the torque control can be achieved by changing the control angles. To prevent the control mode from oscillating between CCC and APC around the base speed $n_{b}$, a hysteresis is deliberately introduced into the controller. Namely, when the speed is increasing, the APC mode is set at the speed of $n_{b}+\Delta n$, whereas the CCC mode is set at the speed of $n_{b}-\Delta n$ when the speed is decreasing. Moreover, because of the nature of current control, the performance will not be significantly affected by the dc bus voltage variation.

The speed is controlled by a digital proportionalintegral (PI) regulator whose output is the torque reference $T_{e}^{*}$. The control angles, namely $\theta_{\text {on }}^{+}, \theta_{\text {off }}^{+}, \theta_{\text {on }}^{-}$, and $\theta_{\text {off }}^{-}$, and the current reference $I^{*}$ are determined from the torque reference by using the aforementioned control strategy. Fig. 6 shows the control block diagram. On top of PI control, other sophisticated control techniques such as neuro-fuzzy control or sliding-mode control can readily be incorporated to handle the parameter variation and system nonlinearities.

\section{DETECTION OF ROTOR POSITION AND SPEED}

In accordance with the operating principle of the DSPM motor, the phase winding should be turned on or off at the specific rotor positions. Hence, the rotor position information is indispensable for proper operation of the DSPM motor. For the motor drive system developed here, the rotor positions are supplied by a position sensor which is composed of a 6-slot disc mounted to the rotor shaft and two opto-couplers attached on the stator housing as shown in Fig. 7(a). The opto-couplers are located $45^{\circ}$ apart from each other along the circumference of the disc. Typical output waveforms of the sensor are shown in Fig. 7(b). When the opto-coupler $S_{p}$ is located at the 


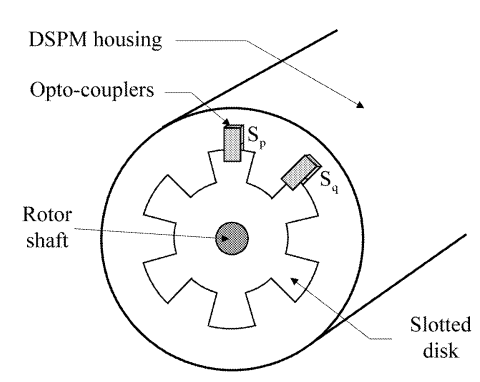

(a)

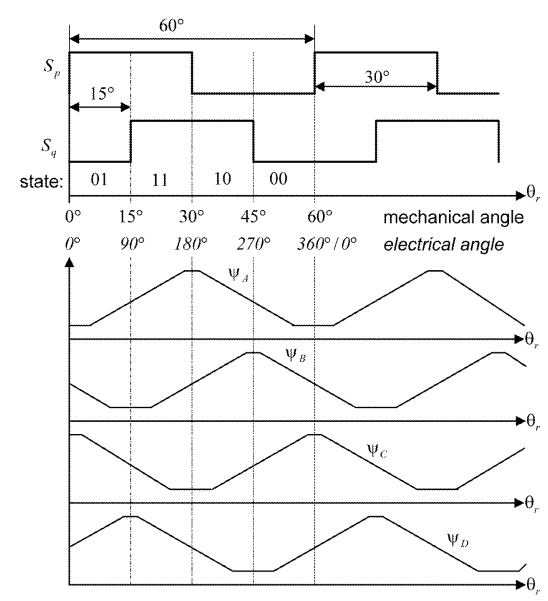

(b)

Fig. 7. Position sensor and its output signals. (a) Sensor location. (b) Position signals and PM flux linkages.

central line of phase A, there is a fixed relationship between the position signals and the PM flux linkages. As shown in Fig. 7(b), the sensor generates a signal edge for each mechanical rotation of $15^{\circ}$. Hence, the transition of the output signal can provide the information of rotor positions.

On the other hand, at each edge, the speed of the motor can readily be calculated by

$$
\hat{n}=\frac{60 \Delta r}{\Delta t}=\frac{f_{\mathrm{clk}}}{0.4 N}
$$

where $\hat{n}$ is the estimated speed in $\mathrm{r} / \mathrm{min}, \Delta r$ the distance between edges in revolution, $\Delta t$ the time between edges, $N$ the number of clock counts between edges, and $f_{\text {clk }}$ the timer- 1 frequency. Since the maximum count error is unity, the higher the $N$ (corresponding to a lower speed), the more accurate the estimated speed is resulted. For the microcontroller of $80 \mathrm{C} 196 \mathrm{KD}$, the $f_{\text {clk }}$ is $1.25 \mathrm{MHz}$ and the maximum count number of a 16-bit operand is $2^{16}=65536$, hence the minimum measurable speed is about $48 \mathrm{r} / \mathrm{min}$. Therefore, the lowest speed in the developed DSPM motor drive based on the $80 \mathrm{C} 196 \mathrm{KD}$ is about $50 \mathrm{r} / \mathrm{min}$.

\section{IMPLEMENTATION}

As a supply to the DSPM motor, the bipolar converter is preferred so as to bring the merit of the
TABLE I

Control Logic

\begin{tabular}{cc|cccc}
\hline \hline Signal states: $S_{q} S_{p}$ & 01 & 11 & 10 & 00 \\
\hline \multirow{2}{*}{ Phase A } & $S_{1}$ & 1 & 1 & 0 & 0 \\
& $S_{2}$ & 0 & 0 & 1 & 1 \\
\hline \multirow{2}{*}{ Phase B } & $S_{3}$ & 0 & 1 & 1 & 0 \\
& $S_{4}$ & 1 & 0 & 0 & 1 \\
\hline \multirow{2}{*}{ Phase C } & $S_{5}$ & 0 & 0 & 1 & 1 \\
& $S_{6}$ & 1 & 1 & 0 & 0 \\
\hline Phase D & $S_{7}$ & 1 & 0 & 0 & 1 \\
& $S_{8}$ & 0 & 1 & 1 & 0 \\
\hline
\end{tabular}

DSPM motor into full play. To control the phase currents individually, there are basically two converter topologies possible for bidirectional operation of the DSPM motor, namely the full-bridge converter and the half-bridge converter with split capacitors. The latter is usually selected for the DSPM drive system, as shown in Fig. 1(b), because it uses the minimum number of power devices. For conventional 3-phase DSPM motors, the connection between the center-point of the split capacitors and the neutral of the motor, as shown by the dotted line in Fig. 1(b), is necessary to accommodate the current flow during the commutation period $[4,5]$. In this converter topology, however, voltage asymmetry between the two split capacitors often occurs due to the asymmetrical inductances for positive and negative currents. As a result, different voltages are supplied to the upper and lower bridge legs, hence degrading the drive performance, increasing the torque ripple, and even damaging the capacitors. Therefore, an auxiliary circuitry is usually adopted to keep the voltage at the center-point of the capacitors constant $[5,10]$, which makes the control system more complicated.

For the proposed 4-phase 8/6-pole DSPM motor, the control logic can be obtained as given in Table I, according to the relationship between the PM flux and the position signal shown in Fig. 7(b). It can be found that at any time instant, the power switches in the upper leg and the lower leg of the converter conduct in pairs (phase A pairs off with phase $\mathrm{C}$, and phase $\mathrm{B}$ pairs off with phase D). Hence, it arises the possibility of removing the connection between the center-point of the split capacitors and the neutral of the motor without causing adverse influence on the performance of the motor drive. As a consequence, the problem of voltage unbalance in the split capacitors is eliminated and the control system is thus simplified.

The hardware of the control system is implemented by an Intel 80C196KD 16-bit single-chip microcontroller. It receives the position signals from the rotor position sensor, and then calculates the motor speed and the firing angles of the converter. The microcontroller also produces the current references 
TABLE II

Motor Parameters

\begin{tabular}{l|c}
\hline \hline Rated power & $750 \mathrm{~W}$ \\
Rated phase voltage & $200 \mathrm{~V}$ \\
Rated speed & $1500 \mathrm{r} / \mathrm{min}$ \\
No. of phases & 4 \\
No. of stator poles & 8 \\
No. of rotor poles & $75 \mathrm{~mm}$ \\
Stator inner diameter & $75 \mathrm{~mm}$ \\
Stack length & $0.45 \mathrm{~mm}$ \\
Airgap length & 220 \\
Winding turns per phase & $\mathrm{Nd}-\mathrm{Fe}-\mathrm{B}$ \\
Magnet material & \\
\multicolumn{2}{c}{ Ratings of DC Dynamometer } \\
\hline Power & $2.3 \mathrm{~kW}$ \\
Voltage & $230 \mathrm{~V}$ \\
Speed & $10 \mathrm{~A}$ \\
\hline \hline
\end{tabular}

to drive the 8 insulated gate bipolar transistor (IGBT) power devices. The phase current is measured by a Hall-effect current sensor, and is fed to a hysteresis current controller via an absolute amplifier.

\section{RESULTS}

An experimental DSPM motor drive has been built for verification. The corresponding motor parameters are listed in Table II. A dc dynamometer is used as the load of the DSPM motor drive, and its ratings are given in Table III. Both the input power and rms current of the DSPM motor are measured by a digital power analyzer. Moreover, under the same parameters and operating conditions, computer simulation waveforms are also generated to verify the experimental waveforms.

Before the experimental machine operating normally as a motor, it first operates as a generator. When it is driven by the dynamometer at $1500 \mathrm{r} / \mathrm{min}$, the simulated and measured no-load back EMF waveforms are shown in Fig. 8. As expected, the agreement between these waveforms is good.

When the motor drive runs below the base speed, the CCC mode is adopted for constant-torque operation. On the other hand, when it runs at or above the base speed, the APC mode is used for constant-power operation. The simulated current waveforms operating in the CCC mode $(500 \mathrm{r} / \mathrm{min}$ and $3 \mathrm{Nm}$ ) and in the APC mode (1500 r/min and $4.5 \mathrm{Nm}$ ) are shown in Fig. 9(a) and Fig. 9(b), respectively. The corresponding measured waveforms are shown in Fig. 10(a) and Fig. 10(b) for comparison. It can be found that the measured waveforms closely agree with the simulated ones. Also, both the simulated and measured waveforms follow the theoretical typical patterns as depicted in Fig. 5.

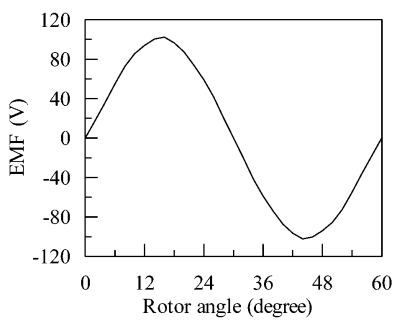

(a)

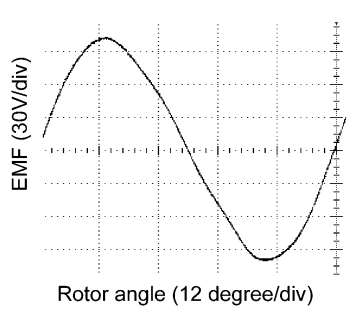

(b)

Fig. 8. No-load back EMF waveforms at speed of $1500 \mathrm{r} / \mathrm{min}$. (a) Simulated. (b) Measured.

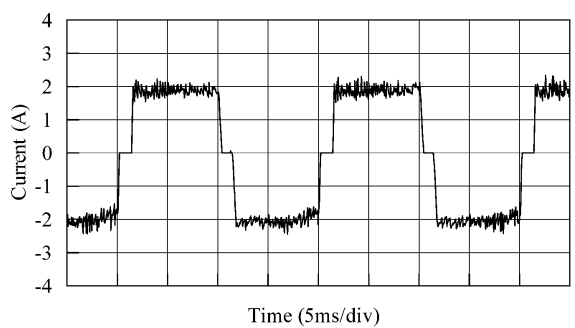

(a)

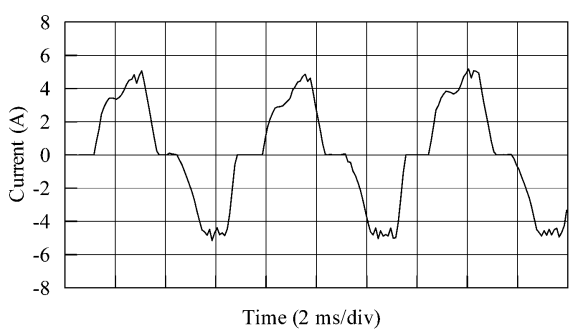

(b)

Fig. 9. Simulated current waveforms. (a) CCC mode at $500 \mathrm{r} / \mathrm{min}$ and $3 \mathrm{Nm}$. (b) APC mode at $1500 \mathrm{r} / \mathrm{min}$ and $4.5 \mathrm{Nm}$.

Fig. 11 illustrates the measured efficiency and RMS current of the proposed motor at the rated speed of $1500 \mathrm{r} / \mathrm{min}$. It can be seen that the motor offers a high efficiency over a wide output power range, which is highly favorable to some specific applications such as EVs. The measured efficiency of the experimental motor at the rated operating point is $87.7 \%$, which is much higher than that of a standard induction motor (typically $75 \%$ ) with the same ratings and frame size.

To testify the dynamic performance of the motor drive, the speed and current responses are recorded. Fig. 12 and Fig. 13 show two kinds of transient responses resulting from computer simulation and experimental measurement, respectively. As expected, the agreement between them is good. One kind is the 


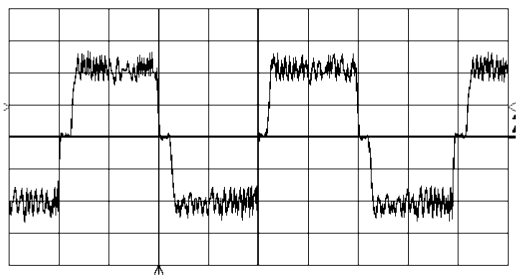

(a)

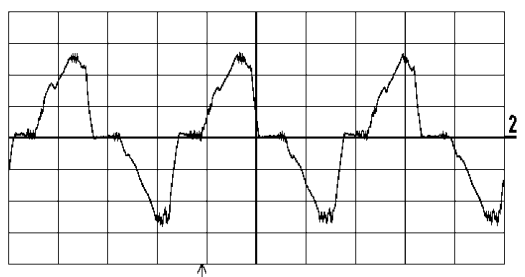

(b)

Fig. 10. Measured current waveforms. (a) CCC mode at $500 \mathrm{r} / \mathrm{min}$ and $3 \mathrm{Nm}(1 \mathrm{~A} / \mathrm{div}, 5 \mathrm{~ms} / \mathrm{div})$. (b) APC mode at $1500 \mathrm{r} / \mathrm{min}$ and $4.5 \mathrm{Nm}$ (2 A/div, $2 \mathrm{~ms} / \mathrm{div})$.

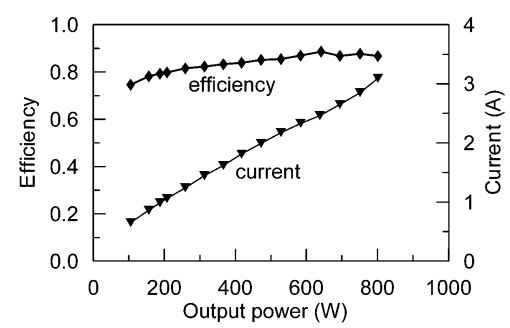

Fig. 11. Measured efficiency and rms current at $1500 \mathrm{r} / \mathrm{min}$.

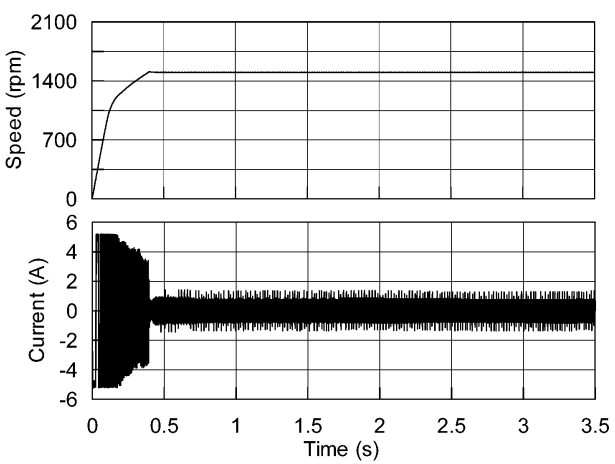

(a)

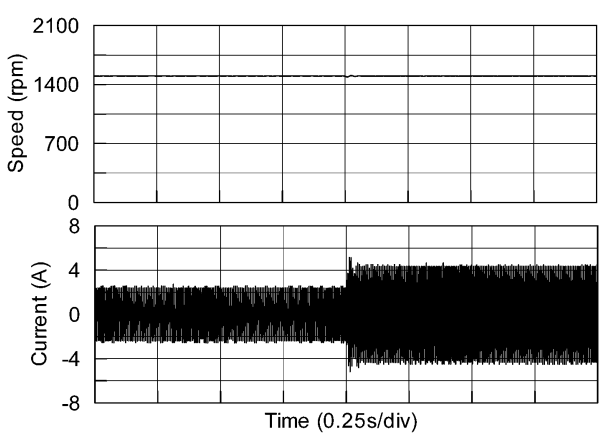

(b)

Fig. 12. Simulated speed and current responses. (a) Start-up at no-load. (b) Sudden change of load torque from $0.66 \mathrm{Nm}$ to $2.66 \mathrm{Nm}$.

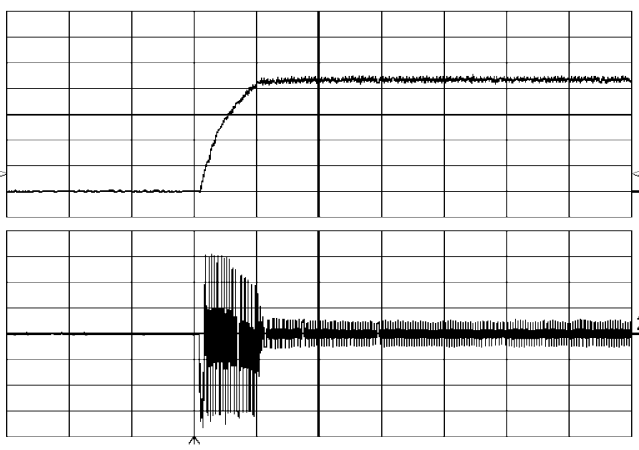

(a)

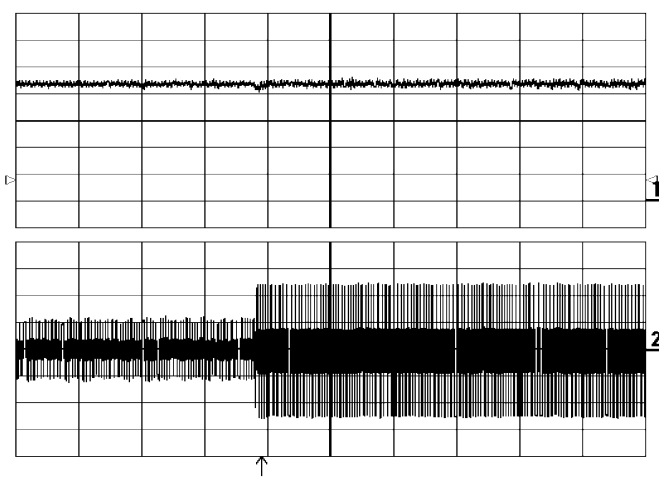

(b)

Fig. 13. Measured speed (upper trace) and current (lower trace) responses. (a) Start-up at no-load $(350 \mathrm{r} / \mathrm{min} / \mathrm{div}, 1.67 \mathrm{~A} / \mathrm{div}$, $0.5 \mathrm{~s} / \mathrm{div}$ ). (b) Sudden change of load torque from $0.66 \mathrm{Nm}$ to $2.66 \mathrm{Nm}$ at $1500 \mathrm{r} / \mathrm{min}(350 \mathrm{r} / \mathrm{min} / \mathrm{div}, 2 \mathrm{~A} / \mathrm{div}, 0.5 \mathrm{~s} / \mathrm{div})$.

start-up transient from standstill to the rated speed of $1500 \mathrm{r} / \mathrm{min}$ under no-load. It can be seen that the motor drive responds quickly and takes less than $0.5 \mathrm{~s}$ to reach the desired speed without any steady-state error. Another kind is the loading transient under a sudden change of load from the minimum inertial load $(0.66 \mathrm{Nm})$ to over the half full-load $(2.66 \mathrm{Nm})$ at the rated speed of $1500 \mathrm{r} / \mathrm{min}$. It can be found that the transient drop in speed is insignificant and the speed regulation is good.

To verify the effectiveness of the proposed split-winding topology, the capability to extend the constant-power operation range and the achievable maximum speed are particularly interesting. Since the available dc dynamometer can only operate up to $2250 \mathrm{r} / \mathrm{min}$ (150\% of the rated speed), the corresponding constant-power operation test of the proposed motor drive needs to be carried out at a reduced voltage level (namely, the dc bus voltage is reduced from $400 \mathrm{~V}$ to $150 \mathrm{~V}$ ). Thus, the whole range of constant-power operation can be evaluated by the available dc dynamometer. During the test, the reference speed is set to its maximum value so that the motor drive runs at its maximum capability. Hence, the achievable speeds under different output powers are recorded. Notice that the output power is controlled by varying the electronic load connected to the terminals of the dc dynamometer. The 


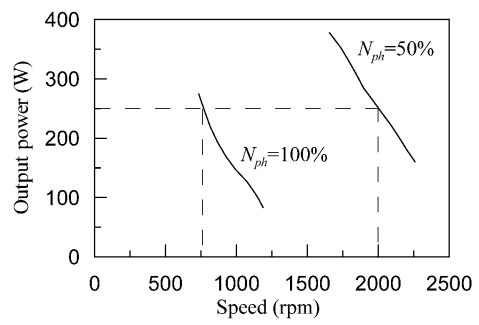

Fig. 14. Measured inherent power-speed characteristics under reduced supply voltage.

corresponding measured power-speed characteristics without and with split-winding operation (namely, $N_{\text {ph }}=100 \%$ and $N_{\text {ph }}=50 \%$ ) are shown in Fig. 14 . It can be found that the proposed DSPM motor drive can signficantly extend the constant-power speed limit when the split-winding topology is adopted. In this case, its speed limit is improved from $750 \mathrm{r} / \mathrm{min}$ to $2000 \mathrm{r} / \mathrm{min}$ for a given output power of $250 \mathrm{~W}$ when the split-winding topology is changed from $100 \%$ to $50 \%$. On the other hand, the achievable maximum speed test of the proposed motor drive under the rated voltage can be directly conducted by mechanically decoupling it from the dc dynamometer. In this test, the speed reference is also set to its maximum value. The measured no-load speed capabilities of the motor drive under the rated voltage are $3152 \mathrm{r} / \mathrm{min}$ and $6010 \mathrm{r} / \mathrm{min}$ when the split-winding arrangements are $100 \%$ and $50 \%$, respectively. Both the tests illustrate that the proposed split-winding topology can effectively extend the operation range of the motor drive.

As mentioned before, the achievable maximum speed of the proposed motor drive is $6010 \mathrm{r} / \mathrm{min}$ under the conditions of no-load, rated voltage and $50 \%$ split-winding. The corresponding waveforms of the firing signal of an upper-leg switch and the phase current are recorded as shown in Fig. 15. It can be observed that the current initially rises up when the back EMF is lower than the supplied voltage. Then, the current falls from a peak due to the excessive PM-induced back EMF. With the rotor rotation, the back EMF becomes lower than the supplied voltage again; hence, the current rises again until the firing signal turns off (namely, the completion of the positive stroke). During the negative stroke, similar phenomena occur except that the current finally increases to a very high value (without enforcing the current limit) because of the negative $d L / d \theta_{r}$. These phenomena can readily be explained by (8).

\section{CONCLUSION}

A new 8/6-pole split-winding DSPM motor drive has been proposed and implemented. The construction and operating principle of the motor have been

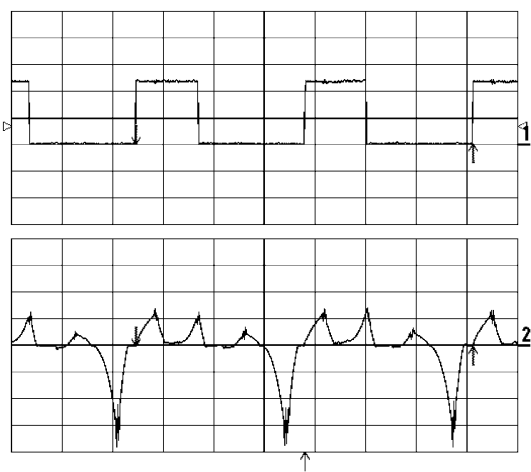

Fig. 15. Measured waveforms of firing signal (upper trace) and current (lower trace) at $6010 \mathrm{r} / \mathrm{min}(2 \mathrm{~V} / \mathrm{div}, 2 \mathrm{~A} / \mathrm{div}, 0.5 \mathrm{~ms} / \mathrm{div})$.

presented. The magnetic field and hence the static characteristics have been analyzed. The control strategy for the motor drive has been developed and implemented by a 16-bit single-chip microcontroller. As a supply to the DSPM motor, the half-bridge power converter has been used to reduce the number of power devices. The whole drive system has been prototyped and tested. The experimental results confirm that the proposed motor drive works at high efficiency over a wide output power range, exhibits good dynamic performance and extends the constant-power operation range significantly. Moreover, the 4-phase 8/6-pole configuration offers the advantage of using the half-bridge power converter without split capacitors, hence avoiding the problem of voltage asymmetry and simplifying both control hardware and software of the motor drive.

\section{REFERENCES}

[1] Elbuluk, M. E., and Kankam, M. D. (1997) Potential starter/generator technologies for future aerospace applications.

IEEE Aerospace and Electronic Systems Magazine, 12, 5 (1997), 24-31.

[2] Chan, C. C., Chau, K. T., Jiang, J. Z., Xia, W., Zhu, M., and Zhang, R. (1996)

Novel permanent magnet motor drives for electric vehicles.

IEEE Transactions on Industrial Electronics, 43, 2 (1996), 331-339.

[3] Chan, C. C., Jiang, J. Z., Chen, G. H., Wang, X. Y., and Chau, K. T. (1994)

A novel polyphase multipole square-wave permanent magnet motor drive for electric vehicles.

IEEE Transactions on Industry Applications, 30, 5 (1994), $1258-1265$

[4] Liao, Y., Liang, F., and Lipo, T. A. (1995)

A novel permanent magnet motor with doubly salient structure.

IEEE Transactions on Industry Applications, 31, 5 (1995), $1059-1078$

[5] Blaabjerg, F., Christensen, L., Rasmussen, P. O.,

Oestergaard, L., and Pedersen, P. (1995)

New advanced control methods for doubly salient permanent magnet motor.

IEEE Industry Applications Society Annual Meeting Record, 1995, 272-230. 

On the dynamic model of a doubly-salient permanent magnet motor.

IEEE Mediterranean Electrotechnical Conference, 1998, 410-414.

[7] Chau, K. T., Cheng, M., and Chan, C. C. (1999)

Performance analysis of 8/6-pole doubly salient permanent magnet motor.

Electric Machines and Power Systems, 27, 10 (1999), 1055-1067.

[8] Cheng, M., Chau, K. T., Chan, C. C., and Zhou, E. (2000) Performance analysis of split-winding doubly salient permanent magnet motor for wide speed operation. Electric Machines and Power Systems, 28, 3 (2000), 277-288.
[9]

Cheng, M., Chau, K. T., and Chan, C. C. (2001)

Design and analysis of a new doubly salient permanent magnet motors.

IEEE Transactions on Magnetics, 37, 4 (2001), 3012-3020.

[10] Huang, J., Zhou, E., and Jiang, Q. (1997)

Analysis and compensation of voltage asymmetry in the split converter of a four-phase switched reluctance motor drive.

IEEE International Conference on Power Electronics and Drive Systems, 1997, 703-707.
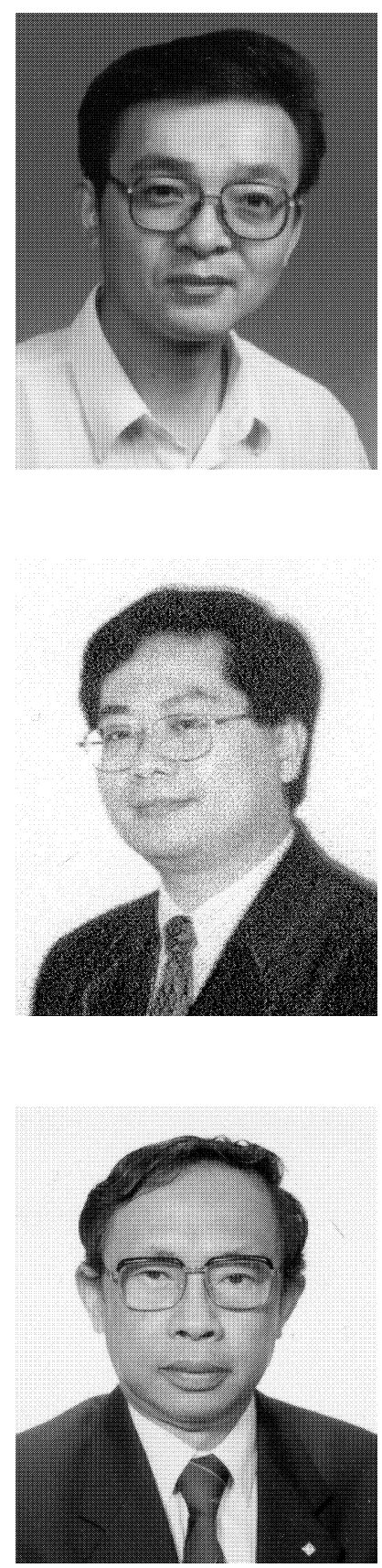

Ming Cheng (M'01-SM'02) received the B.Sc.(Eng.) and M.Sc.(Eng.) degrees from the Department of Electrical Engineering, Southeast University (formerly Nanjing Institute of Technology), China, in 1982 and 1987, respectively, and the Ph.D. degree from the Department of Electrical and Electronic Engineering, The University of Hong Kong in 2001.

He is currently the head and professor of the Department of Electrical Engineering, Southeast University, China. His teaching and research interests include electrical machines, motor drives and power electronics.

Dr. Cheng has published over 50 technical papers and reports, and holds 4 patents.

K. T. Chau (M'89) received his first-class honors B.Sc.(Eng.), M.Phil. and Ph.D. degrees in electrical and electronic engineering from the University of Hong Kong.

Currently, he works as Associate Professor in the Alma Mater. His teaching and research interests focus on three main areas-power converters, machines and drives, and electric vehicles.

Dr. Chau has published over a hundred refereed technical papers and many industrial reports. He has also served as chairs and organizing committee members for many international conferences. He is the coauthor of a monograph Modern Electric Vehicle Technology (Oxford University Press).

C. C. Chan (M'77-SM'77-F'92) received the B.Sc. degree from China University of Mining and Technology, Beijing, China, the M.Sc. degree from Tsinghua University, Beijing, China, and the Ph.D. degree from the University of Hong Kong, Hong Kong, in 1953, 1957 and 1981 respectively, and was awarded the Honorary D.Sc. degree from the University of Odessa in 1992.

$\mathrm{He}$ is currently Chair Professor in the Department of Electrical and Electronic Engineering, University of Hong Kong.

Dr. Chan has authored 4 books, published over 120 technical papers, and holds 7 patents. He is also a Fellow of the Royal Academy of Engineering, U.K., and an Academician of the Chinese Academy of Engineering. 